\title{
Efficacy of regulatory T-cell immunotherapy: are inflammatory cytokines key determinants?
}

\section{Jagadeesh Bayry, Sébastien Lacroix-Desmazes, Suryasarathi Dasgupta, Michel D. Kazatchkine and Srini V. Kaveri}

We read with interest the recent article in Nature Reviews Immunology by MariaGrazia Roncarolo and Manuela Battaglia, which summarizes our current knowledge of regulatory $\mathrm{T}$ cells and the possibilities of using such cells in immunotherapeutic protocols for preserving or restoring tolerance to self antigens and alloantigens in humans ${ }^{1}$. Because of the low numbers of antigenspecific regulatory $\mathrm{T}$ cells in the circulation and the difficulties in obtaining them, the most favoured approach for regulatory T-cell immunotherapy is the in vitro expansion of polyclonal regulatory $\mathrm{T}$ cells. As described in this Review, from the perspective of preventive therapy, regulatory T-cell immunotherapy, for example, represents a promising approach to avoid transplant rejection. However, considering the intrinsic defects in regulatory T-cell functions in several autoimmune diseases, the approach of regulatory T-cell immunotherapy proposed by the authors might not be efficacious for curing ongoing acute and chronic inflammatory and autoimmune diseases. We therefore suggest an alternative strategy for regulatory T-cell immunotherapy, which involves a primary step of induction of functionally fit regulatory $\mathrm{T}$ cells in patients, followed by in vitro expansion of these induced polyclonal regulatory $\mathrm{T}$ cells for therapeutic purposes.

Several recent studies have analysed the role and function of naturally occurring forkhead box P3 (FOXP3) ${ }^{+} \mathrm{CD} 4{ }^{+} \mathrm{CD} 25^{+}$ regulatory $\mathrm{T}$ cells (referred to as natural $\mathrm{T}_{\text {Reg }}$ cells) in experimental models of arthritis and in patients with rheumatoid arthritis, both at acute and chronic stages of the disease ${ }^{2}$. One of the major findings is that the frequency of natural $\mathrm{T}_{\text {Reg }}$ cells is higher in the inflamed joints than in peripheral blood of patients with rheumatoid arthritis. The reasons for the increased frequencies of these cells in the inflamed synovia are not known. In addition to preferential homing to synovia from peripheral blood, it is possible that the $\mathrm{T}_{\mathrm{Reg}}$-cell population expands within the synovia under the influence of cytokines ${ }^{2}$. Nevertheless, the occurrence of persistent inflammation in rheumatoid joints despite the presence of increased $\mathrm{T}_{\text {Reg }}$-cell numbers indicates that these cells are ineffective in controlling the ongoing inflammatory response. Although activated human dendritic cells are susceptible to suppression by natural $\mathrm{T}_{\text {Reg }}$ cells in vitro ${ }^{3,4}$, pro-inflammatory cytokines, in particular tumour-necrosis factor (TNF), secreted by activated monocytes and macrophages can suppress the functions of natural $\mathrm{T}_{\text {Reg }}$ cells and render them defective $e^{5-7}$. This inhibition has been shown to involve signalling through TNF receptor type II, which is constitutively expressed by unstimulated natural $\mathrm{T}_{\text {Reg }}$ cells and is upregulated by $\mathrm{TNF}^{6}$. TNFmediated inhibition of suppressive function has also been associated with a decrease in the expression of FOXP3 by natural $\mathrm{T}_{\text {Reg }}$ cells isolated from patients with active rheumatoid arthritis. These results may explain why most studies involving the adoptive transfer of natural $\mathrm{T}_{\text {Reg }}$ cells in experimental settings have shown therapeutic efficacy only at early stages of arthritis or when used as a preventive therapy, but have not been effective in curing established disease $\mathrm{e}^{1,8-10}$.

Consistent with the inhibitory effect of TNF on natural $\mathrm{T}_{\mathrm{Reg}}$-cell function, treatment of patients with rheumatoid arthritis with TNF-specific monoclonal antibodies has been shown to be associated with a significant increase in the number of peripheral-blood regulatory $\mathrm{T}$ cells in patients who responded to this treatment compared with those who did not respond ${ }^{5,6}$. However, this increase was due to the generation of a newly differentiated population of regulatory T cells, which exert their suppressive function by secreting transforming growth factor- $\beta$ and interleukin-10 (IL-10) ${ }^{11}$. The absence of CD62L expression on these cells marked them as phenotypically distinct from the natural $\mathrm{T}_{\mathrm{Reg}}$ cells present in patients with active rheumatoid arthritis. Whereas such 'induced', CD62 $\mathrm{L}^{-}$regulatory T cells display potent suppressor capacity, the $\mathrm{CD}_{62} \mathrm{~L}^{+}$natural $\mathrm{T}_{\mathrm{Reg}}$ cells remained defective in patients treated with TNF-specific monoclonal antibodies. These results suggest that natural
$\mathrm{T}_{\text {Reg }}$ cells are defective in rheumatoid arthritis, and perhaps also other autoimmune and inflammatory diseases such as multiple sclerosis and type 1 diabetes ${ }^{11-13}$. Therefore, immunotherapy approaches involving the adoptive transfer of these defective natural $\mathrm{T}_{\mathrm{Reg}}$ cells after expansion ex vivo might not be beneficial, as such cells are unlikely to be efficient at restoring self tolerance in patients with established disease.

Given the intrinsic defects in the natural $\mathrm{T}_{\text {Reg }}$-cell compartment in several autoimmune diseases, therapeutic modulation of the regulatory $\mathrm{T}$-cell compartment in vivo would appear a more plausible and promising approach. We therefore propose that an important strategy for restoring tolerance in patients with established autoimmune diseases would be to inhibit the activity or production of pro-inflammatory cytokines in vivo through pharmaceutical or biological agents $^{14}$, such as TNF-specific antibody, and to induce functional regulatory $\mathrm{T}$ cells de novo ${ }^{8}$. It is however worth noting that patients with rheumatoid arthritis were found to relapse shortly after withdrawal of TNF-specific therapy ${ }^{15}$. This indicates that despite reducing the joint inflammation and inducing functional regulatory $\mathrm{T}$ cells, tolerance imparted by therapeutic monoclonal antibody therapy is of short duration. Nevertheless, functional regulatory T cells are already induced in these patients as a consequence of neutralization of inflammatory environment by monoclonal antibodies. We therefore suggest that such functionally competent, induced regulatory cells may then be considered for immunotherapy protocols to achieve long-term immune tolerance.

Jagadeesh Bayry, Sébastien Lacroix-Desmazes, Suryasarathi Dasgupta, Michel D. Kazatchkine and Srini V. Kaveri are at the Institut National de la Santé et de la Recherche Médicale (INSERM) UMR S872 Equipe 16: Immunopathology and Therapeutic Intervention, Centre de Recherche des Cordeliers, Université Pierre et Marie Curie, 15 rue de l'Ecole de Médicine, Paris, F-75006, France, Université Paris Descartes, INSERM, U 872, Paris, F-75006, France. Correspondence to J.B. e-mail: jagadeesh.bayry@crc.jussieu.fr doi:10.1038/nri2138-c1

1. Roncarolo, M-C \& Battaglia, M. Regulatory Tcell immunotherapy for tolerance to self antigens and alloantigens in humans. Nature Rev. Immunol. 7, 585-598 (2007)

2. Leipe, J., Skapenko, A., Lipsky, P. E. \& Schulze-Koops, H. Regulatory T cells in rheumatoid arthritis. Arthritis Res. Ther. 7, 93-99 (2005).

3. Houot, R., Perrot, I., Garcia, E., Durand, I. \& Lebecque, S. Human $\mathrm{CD} 4^{+} \mathrm{CD} 25^{\text {high }}$ regulatory $\mathrm{T}$ cells modulate myeloid but not plasmacytoid dendritic cells activation. J. Immunol. 176, 5293-5298 (2006) 4. Bayry, J., Triebel, F., Kaveri, S. V. \& Tough, D. F. Human dendritic cells acquire a semimature phenotype and lymph node homing potential through interaction with CD 4 ${ }^{+} \mathrm{CD} 25^{+}$regulatory T cells. J. Immunol. 178, 4184-4193 (2007). 
5. Ehrenstein, M. R. et al. Compromised function of regulatory $T$ cells in rheumatoid arthritis and reversal by anti-TNF- $\alpha$ therapy. J. Exp. Med. 200, 277-285 (2004).

6. Valencia, X. et al. TNF downmodulates the function of human $C D 4+C D 25^{\text {hi }}$ T-regulatory cells. Blood 108 , 253-261 (2006)

7. van Amelsfort, J. M. et al. Proinflammatory mediator induced reversal of $\mathrm{CD}^{+}, \mathrm{CD} 25^{+}$regulatory $\mathrm{T}$ cellmediated suppression in rheumatoid arthritis. Arthritis Rheum. 56, 732-742 (2007).

8. Bayry, J., Siberil, S., Triebel, F., Tough, D. F. \& Kaveri, S. V. Rescuing $\mathrm{CD} 4{ }^{+} \mathrm{CD} 25^{+}$regulatory T-cell functions in rheumatoid arthritis by cytokine-targeted monoclonal antibody therapy. Drug Discov. Today 12 548-552 (2007)

9. Frey, O. et al. The role of regulatory T cells in antigeninduced arthritis: aggravation of arthritis after depletion and amelioration after transfer of CD4 ${ }^{+} \mathrm{CD} 25^{+} \mathrm{T}$ cells. Arthritis Res. Ther. 7 , R291-R301 (2005).

10. Bardos, T. et al. $\mathrm{CD} 4{ }^{+} \mathrm{CD} 25+$ immunoregulatory $\mathrm{T}$ cells may not be involved in controlling autoimmune arthritis. Arthritis Res. Ther. 5, R106-R113 (2003).

11. Nadkarni, S., Mauri, C. \& Ehrenstein, M. R Anti-TNF- $\alpha$ therapy induces a distinct regulatory $\mathrm{T}$ cell population in patients with rheumatoid arthritis via TGF- $\beta$. J. Exp. Med. 204, 33-39 (2007).

12. Viglietta, V., Baecher-Allan, C., Weiner, H. L. \& Hafler D. A. Loss of functional suppression by $\mathrm{CD} 4{ }^{+} \mathrm{CD} 25+$ regulatory $\mathrm{T}$ cells in patients with multiple sclerosis. J. Exp. Med. 199, 971-979 (2004).

13. Lindley, S. et al. Defective suppressor function in CD4 ${ }^{+} \mathrm{CD} 25^{+}$T-cells from patients with type 1 diabetes. Diabetes 54, 92-99 (2005).
14. Bayry, J., Lacroix-Desmazes, S., Kazatchkine, M. D. \& Kaveri, S. V. Monoclonal antibody and intravenous immunoglobulin therapy for rheumatic diseases: rationale and mechanisms of action. Nature Clin. Pract. Rheumatol. 3, 262-272 (2007).

15. Buch, M. H., Marzo-Ortega, H., Bingham, S. J. \& Emery, P. Long-term treatment of rheumatoid arthritis with tumour necrosis factor $\alpha$ blockade: outcome of ceasing and restarting biologicals. Rheumatology (Oxford) 43, 243-244 (2004).

Acknowledgements:

Supported by grants from the Institut National de la Santé et de la Recherche Médicale (INSERM), Centre National de la Recherche Scientifique (CNRS), UPMC-Paris VI, France, and Agence Nationale de la Recherche (ANR; JC07-184110), France. 